\title{
OPTIMAL ALLOCATION OF AIRPLANES TO ROUTES
}

\author{
E.K. Vasermanis, N. A. Nechval, K. N. Nechval
}

Mathematical Statistics Department, University of Latvia, Raina Blvd 19, LV-1050 Riga, Latvia.

E-mail:nechval@junik.lv

Received 2711 2002, accepted 26022004

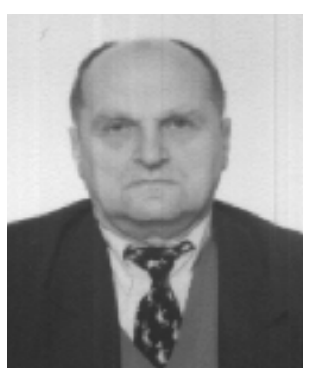

Edgars K. VASERMANIS received a PhD degree in automatic control and systems engineering from the Riga Civil Aviation Engineers Institute (RCAEI) in June 1974, and a DSc degree in economics and management from Tallinn University in September 1989. He is now a Dean of the Faculty of Economics and Management at the University of Latvia. His interests include economics and management, operations research, statistical decision theory, and adaptive control. Professor Vasermanis is a professional member of the Latvian Statistical Association and the Institute of Mathematical Statistics. He is a member of the Latvian Association of Professors.

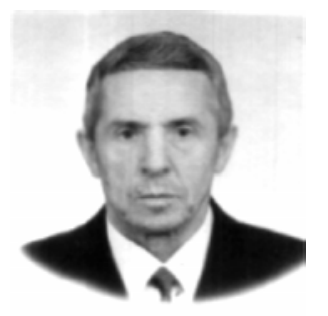

Nicholas A. NECHVAL received a PhD degree in automatic control and systems engineering from the Riga Civil Aviation Engineers Institute (RCAEI) in June 1969, and a DSc degree in radio engineering from Riga Aviation University (RAU) in June 1993. Dr. Nechval was Professor of Applied Mathematics at RAU from 1993 to 1999. At present, he is Professor of Mathematics and Computer Science at the University of Latvia, Riga, Latvia. In 1992, Dr. Nechval was awarded a Silver Medal of the Exhibition Committee (Moscow, Russia) in connection with research on the problem of Prevention of Collisions between Aircraft and Birds. He is the holder of several patents in this field. His interests include mathematics, stochastic processes, pattern recognition, multidimensional statistic detection and estimation, multiresolution stochastic signal analysis, digital radar signal processing, operations research, statistical decision theory, and adaptive control. Professor Nechval is a professional member of the Latvian Statistical Association, the Institute of Mathematical Statistics, and CHAOS asbl (the Institute of Mathematics, based in Liege, Belgium). Dr. Nechval is also a member of the Latvian Association of Professors.

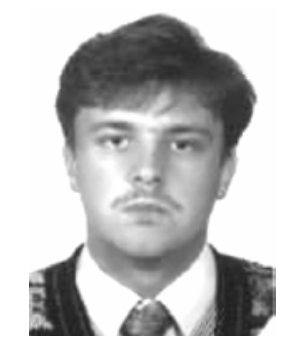

Konstantin N. NECHVAL was born in Riga, Latvia, on March 5, 1975. He received a MS degree from the Aviation University of Riga, Latvia, in 1998. At present, he is a $\mathrm{PhD}$ student in automatic control and systems engineering at Riga Technical University. His research interests include stochastic processes, pattern recognition, operations research, statistical decision theory, and adaptive control.

Abstract. In this paper, we introduce a model that can assist airline planners in deploying their fleets as efficiently as possible. Specifically, we outline an optimization model that assigns a fleet of aircraft of different types to routes to maximize profits. An algorithm for solving nonlinear transportation problem is suggested. It is based on the use of Lagrange multipliers. We define and illustrate the use of the loss function, the cost structure of which is piecewise linear. The necessary and sufficient conditions for optimality are given. To illustrate the proposed approach, a numerical example is given.

Keywords: airline network, transportation system, routes, aircraft assignment problem, profit maximization.

\section{Introduction}

A critical determinant of an airline's survival in today's competitive environment is its ability to utilize its resources efficiently. Critical resources available to an airline include its personnel or crews, its gates and airport slots and its aircraft. In many hub and spoke airline planning contexts, the assignment of aircraft to routes follows the determination of: (1) what cities are to be served, (2) the frequency of service between the hub and each of the other cities, (3) the desired departure and arrival times into and out of the hub for each route by aircraft type, and (4) the potential profit associated with assigning each route to each different type of aircraft in the fleet. For international carriers, many of these decisions are heavily constrained by bilateral agreements, the availability of gate space in foreign airports, airport restrictions and operating regulations, and so on. Thus, in 
practice, there are relatively few options available to planners with regard to these decisions. The primary source of leverage for such carriers in the short term is their ability to choose which aircraft to assign to each route. In this paper, we introduce a model that can assist airline planners in deploying their fleets as efficiently as possible. Specifically, we outline an optimization model that assigns a fleet of aircraft of different types to routes to maximize profits.

The problem considered in this paper is the following. An airline company operates more than one route. It has more than one type of airplanes available. Each type has its relevant capacity and costs of operation. The passenger demand on each route is known in the form of a distribution function, and the question asked is: Which aircraft should be allocated to which route in order to minimize the total cost (performance index) of operation? This latter involves two kinds of costs: the costs connected with running and servicing an airplane, and the costs incurred whenever a passenger is denied transportation because of lack of seating capacity. (This latter cost is the so-called "opportunity" cost.)

In this paper, we define and illustrate the use of the loss function, the cost structure of which is piecewise linear. Within the context of this performance index, we assume that a distribution function of the passenger demand on each route is known. Thus, we develop our discussion of the allocation problem in the presence of completely specified demand distributions. We formulate this problem in a probabilistic setting. The necessary and sufficient conditions for optimality are given.

\section{Problem Statement}

Let $A_{1}$, Ak be the set of airplanes, which a company utilize to satisfy the passenger demand for transportation on routes $1, \mathrm{~m}$. It is assumed that the company operates $\mathrm{m}$ routes which are of different lengths, and consequently, different profit abilities. Let $f_{j}(x)$ represent the probability density function of the passenger demand $\mathrm{X}$ for transportation on route $\mathrm{j}(\mathrm{j}=1, \mathrm{~m})$; and $\mathrm{F}_{\mathrm{j}}(\mathrm{x})$ its cumulative distribution function.

It is required to minimize the expected total cost of operation (the performance index)

$$
J(\mathbf{U})=\sum_{j=1}^{m}\left[\sum_{i=1}^{k} w_{i j} u_{i j}+c_{j} \int_{Q_{j}}^{\infty}\left(x-Q_{j}\right) f_{j}(x) d x\right]
$$

subject to

$$
\sum_{j=1}^{m} u_{i j} \leq a_{i}, \quad i=1, \ldots, k, \quad u_{i j} \geq 0
$$

where

$$
Q_{j}=\sum_{i=1}^{k} u_{i j} q_{i j}, j=1, \ldots, m,
$$

$\mathbf{U}=\left\{\mathrm{u}_{\mathrm{ij}}\right\}$ is the $\mathrm{k} \times \mathrm{m}$ matrix, $\mathrm{u}_{\mathrm{ij}}$ is the number of units of airplane $A_{i}$ allocated to the $j$ th route, $w_{i j}$ is the

operation costs of airplane $A_{i}$ for the $j$ th route, $c_{j}$ is the price of a one-way ticket for air travel on $j$ th route, $q_{i j}$ is the limited seating capacity of airplane $A_{i}$ for the $j$ th route, $a_{i}$ is available the number of units of airplane $A_{i}$.

The solution of the aforementioned programming problem can be divided into two parts: The first deals with the existence of a minimum and tests of optimality, while the second presents an algorithm for arriving at the optimal program in a reasonable number of steps.

\section{Existence of a Minimum}

The question of the existence of a minimum to the function $\mathbf{J}(\mathbf{u})$ can be easily answered by means of the following lemma.

Lemma 1. The functions $\mathrm{J}(\mathbf{U})$ and $\mathrm{g}_{\mathrm{i}}(\mathbf{U})$ are convex in $\mathbf{U}$, where

$$
\mathrm{g}_{\mathrm{i}}(\mathbf{U})=\mathrm{a}_{\mathrm{i}}-\sum_{\mathrm{j}=1}^{\mathrm{m}} \mathrm{u}_{\mathrm{ij}} \geq 0
$$

Proof. It is easy to see that $\mathrm{g}_{\mathrm{i}}(\mathbf{U})$ is convex, by linearity. Concerning the cost function $\mathbf{J}(\mathbf{U})$, it is clearly continuous and twice differentiable in $\mathbf{U}$. It is known that $\mathbf{J}(\mathbf{U})$ is convex in $\mathbf{U}$ if, and only if, the determinant

$$
\left|\partial^{2} \mathbf{J} / \partial \mathrm{u}_{\mathrm{ij}} \partial \mathrm{u}_{\mathrm{rj}}\right| \geq 0
$$

for all segments of $\mathbf{U}$. But we have

$$
\partial J / \partial u_{i j}=w_{i j}-c_{j} q_{i j} \int_{Q_{j}}^{\infty} f_{j}(x) d x,
$$

$$
\partial \mathrm{J} / \partial \mathrm{u}_{\mathrm{ij}} \partial \mathrm{u}_{\mathrm{rj}}=\mathrm{c}_{\mathrm{j}} \mathrm{q}_{\mathrm{ij}} \mathrm{q}_{\mathrm{rj}} \mathrm{f}_{\mathrm{j}}\left(\mathrm{Q}_{\mathrm{j}}\right)
$$

for $i=1, \ldots k ; j=1, m ; r=1, k$. Then the values of the determinant (5) for all segments of $\mathbf{U}$ may by written in the form of the following matrix:

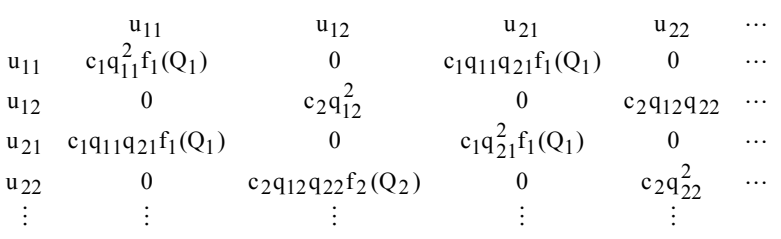

It is clear that the determinant of any square segment of the matrix (8) is $>0$ or $=0$ according to whether it contains an even or an odd number of rows. Thus

$$
\left|\partial^{2} \mathrm{~J} / \partial \mathrm{u}_{\mathrm{ij}} \partial \mathrm{u}_{\mathrm{rj}}\right| \text { is } \geq 0 \text {, as was to be shown. }
$$

This lemma, when combined with the previously mentioned results, also indicates that the solution to the allocation problem requires a "pure strategy" on the part of each "player" in the game theoretic interpretation of the problem. It is important to note that the solution would be unique if the Lagrangian function

$$
\mathrm{L}(\mathbf{U}, \mathbf{s})=\mathrm{J}(\mathbf{U})-\sum_{\mathrm{i}=1}^{\mathrm{k}} \mathrm{s}_{\mathrm{i}} \mathrm{g}_{\mathrm{i}}\left(\mathbf{u}_{\mathrm{i}}\right)
$$


were strictly convex in $\mathbf{U}=\left(\mathbf{u}_{1}, \mathbf{u}_{\mathbf{k}}\right)^{\prime}$, where $\mathbf{u}_{\mathrm{i}}=\left(\mathrm{u}_{\mathrm{i} 1}\right.$, $\left.\mathrm{u}_{\mathrm{im}}\right)^{\prime}, \mathrm{i}=1(1) \mathrm{k}$, and strictly convex in $\mathbf{s}=\left(\mathrm{s}_{1}, \mathrm{sk}\right)^{\prime}$.

\section{Necessary and Sufficient Conditions for Optimality}

For our discussion to have any practical content, proofs of existence should be coupled with practical means for obtaining the optimal. The following theorem provides the necessary and sufficient conditions for optimality and also yields great insight into the iterative procedure in order to arrive at the optimal.

Theorem 1. For a feasible solution $\mathbf{U}^{*}$ to be optimal (i.e., provide a solution to the minimization problem), it is necessary that:

(i) if the inequality $g_{i}\left(\mathbf{u}_{i}^{*}\right)>0$ holds for some $\mathrm{i}$, then the partial derivative of $\mathrm{J}$ with respect to each component of $\mathbf{u}_{\mathrm{i}}{ }^{*}$ which is $>0$ and is involved in the inequality must vanish;

(ii) if the equality $\mathrm{g}_{\mathrm{i}}\left(\mathbf{u}_{\mathrm{i}}^{*}\right)=0$ holds for some $\mathrm{i}$, then the partial derivative of $\mathrm{J}$ with respect to all the components of $\mathbf{u}_{\mathrm{i}}{ }^{*}$ which are $>0$ and are involved in the equality must be the same value $-\mathrm{s}_{\mathrm{i}}\left(\mathrm{s}_{\mathrm{i}} \geq 0\right)$.

The above two conditions, together with the following two conditions are sufficient for optimality:

(iii) in case (i), the partial derivative of $\mathrm{J}$ with respect to each component of $\mathbf{u}_{\mathbf{i}}{ }^{*}$ which is $=0$ and is involved in the same inequality must be $\geq 0$;

(iiii) in case (ii), the partial derivative of $\mathrm{J}$ with respect to all the components of $\mathbf{u}_{\mathbf{i}}{ }^{*}$ which are $=0$ and are involved in the same equality must be $\geq-\mathrm{s}_{\mathrm{i}}$.

Proof. The proof of necessity is accomplished by the use of Lagrange multipliers. Rewrite

$$
\mathrm{g}_{\mathrm{i}}\left(\mathrm{u}_{\mathrm{ij}}, \mathrm{u}_{\mathrm{i} 0}\right)=\mathrm{a}_{\mathrm{i}}-\left(\sum_{\mathrm{j}} \mathrm{u}_{\mathrm{ij}}+\mathrm{u}_{\mathrm{i} 0}\right),
$$

where $u_{i 0}$ are slack variables. Clearly, in case (i) above, $\mathrm{u}_{\mathrm{i} 0}>0$ while in case (ii), $\mathrm{u}_{\mathrm{i} 0}=0$. Consider then the Lagrangian equation

$$
\mathrm{L}\left(\mathrm{u}_{\mathrm{ij}}, \mathrm{u}_{\mathrm{i} 0}, \mathrm{~s}_{\mathrm{i}}\right)=\mathrm{J}\left(\mathrm{u}_{\mathrm{ij}}\right)-\sum_{\mathrm{i}=1}^{\mathrm{k}} \mathrm{s}_{\mathrm{i}} \mathrm{g}_{\mathrm{i}}\left(\mathrm{u}_{\mathrm{ij}}, \mathrm{u}_{\mathrm{i} 0}\right) .
$$

It is well known (Nechval [1-5]) that the required optimum is the solution to the set of simultaneous equations

$$
\begin{aligned}
& \partial \mathrm{L} / \partial \mathrm{u}_{\mathrm{ij}}=0, \\
& \partial \mathrm{L} / \partial \mathrm{u}_{\mathrm{i} 0}=0,
\end{aligned}
$$

and the set of constraining equations. In the case (i) we have $\mathrm{u}_{\mathrm{i} 0}>0$, and (12) yields

$\partial \mathrm{L} / \partial \mathrm{u}_{\mathrm{ij}}=\partial \mathrm{J} / \partial \mathrm{u}_{\mathrm{ij}}+\mathrm{s}_{\mathrm{i}}=0$

while (13) yields

$$
\partial \mathrm{L} / \partial \mathrm{u}_{\mathrm{i} 0}=0+\mathrm{s}_{\mathrm{i}}=0 \text {. }
$$

Therefore $\mathrm{s}_{\mathrm{i}}=0$, and consequently $\partial \mathrm{J} / \partial \mathrm{u}_{\mathrm{ij}}=0$, for all $\mathrm{u}_{\mathrm{ij}}$ involved in the same restriction at positive level. In case (ii), $\mathrm{u}_{\mathrm{i} 0}=0$, and hence

$$
\partial \mathrm{J} / \partial \mathrm{u}_{\mathrm{ij}}+\mathrm{s}_{\mathrm{i}}=0
$$

for all $\mathrm{u}_{\mathrm{ij}}$ involved in the same restriction $\mathrm{g}_{\mathrm{i}}$ at positive level. Therefore $\partial \mathrm{J} / \partial \mathrm{u}_{\mathrm{ij}}$ has the same value, namely $-\mathrm{s}_{\mathrm{i}} \quad\left(\mathrm{s}_{\mathrm{i}} \geq 0\right)$, for all $\mathrm{u}_{\mathrm{ij}}$ involved in the same restriction at positive level. This completes the proof of necessity.

To prove the sufficiency of the conditions, we need to prove that under the conditions of the theorem $\mathrm{J}(\mathbf{u}) \geq \mathrm{J}$ $\left(\mathbf{u}^{*}\right)$. Let $\mathbf{u}^{+}$denote the components of $\mathbf{u}^{*}$ which are at positive level, then

$$
\frac{\partial \mathbf{J}}{\partial \mathbf{u}_{\mathrm{ij}}^{+}} \leq 0, \quad \frac{\partial \mathbf{J}}{\partial \mathbf{u}_{\mathrm{ij}}^{+}} \mathrm{u}_{\mathrm{ij}}^{+} \leq 0, \quad \mathbf{U}^{*} \geq \mathbf{0} .
$$

In the matrix $\mathbf{U}^{*}$, we can assume, without loss of generality since the solution does not depend on the numbering of the rows, that rows $1,2, \mathrm{r}$ are the rows associated with the variables whose sums reach the limits of their respective availability restrictions, i.e.,

$$
\sum_{j=1}^{m} u_{i j}^{*}=a_{i} \text { for } i=1, \ldots, r .
$$

The remaining (k-r) rows contain vectors such that

$$
\sum_{j=1}^{m} u_{i j}^{*}<a_{i} \quad \text { for } i=r+1, \ldots, k .
$$

In the ith row satisfying (18), let $u_{i 1}^{*}, \ldots, u_{i v(i)}^{*}$ be the allocations $>0$, and let $\mathrm{u}_{\mathrm{iv}(\mathrm{i})+1}^{*}, \ldots, \mathrm{u}_{\mathrm{im}}^{*}$ be the allocations $=0$. It follows immediately that

$$
\sum_{j=1}^{v(i)} u_{i j}^{*}=a_{i},
$$

with $\mathrm{v}$ (i) varying from row to row.

An immediate consequence of the conditions of Theorem 1 is the following relationships among the partial derivatives

$\partial \mathrm{J} / \partial \mathrm{u}_{\mathrm{ij}}^{*}=\partial \mathrm{J} / \partial \mathrm{u}_{\mathrm{i} 1}^{*}, \quad \mathrm{j}=1(1) \mathrm{v}(\mathrm{i})$,

$\partial \mathbf{J} / \partial \mathrm{u}_{\mathrm{ij}}^{*} \leq \partial \mathrm{J} / \partial \mathrm{u}_{\mathrm{i} \eta}^{*}, \quad \eta=\mathrm{v}(\mathrm{i})+1(1) \mathrm{m}, \quad \mathrm{i}=1(1) \mathrm{r}$;

$\partial \mathrm{J} / \partial \mathrm{u}_{\mathrm{ij}}^{*}=0, \quad \mathrm{j}=1(1) \mathrm{v}(\mathrm{i})$,

$\partial \mathrm{J} / \partial \mathrm{u}_{\mathrm{ij}}^{*} \geq 0, \quad \eta=\mathrm{v}(\mathrm{i})+1(1) \mathrm{m}, \quad \mathrm{i}=\mathrm{r}+1(1) \mathrm{k}$.

Since $\mathbf{J}(\mathbf{U})$ is convex in $\mathbf{U}$ (see Lemma 1), then

$$
\mathrm{J}(\mathbf{U}) \geq \mathrm{J}\left(\mathbf{U}^{*}\right)+\sum_{\mathrm{i}=1}^{\mathrm{k}} \sum_{\mathrm{j}=1}^{\mathrm{m}} \frac{\partial \mathrm{J}}{\partial \mathrm{u}_{\mathrm{ij}}^{*}}\left(\mathrm{u}_{\mathrm{ij}}-\mathrm{u}_{\mathrm{ij}}^{*}\right) .
$$


But for $\mathrm{i}=1(1) \mathrm{r}$ we have

$$
\begin{aligned}
& \sum_{j=1}^{m} \frac{\partial J}{\partial u_{i j}^{*}}\left(u_{i j}-u_{i j}^{*}\right)=\frac{\partial J}{\partial u_{i 1}^{*}} \sum_{j=1}^{v(i)}\left(u_{i j}-u_{i j}^{*}\right) \\
& +\sum_{j=v(i)+1}^{m} \frac{\partial J}{\partial u_{i j}^{*}}\left(u_{i j}-u_{i j}^{*}\right) \\
& =\frac{\partial J}{\partial u_{i 1}^{*}} \sum_{j=1}^{v(i)} u_{i j}-\frac{\partial J}{\partial u_{i 1}^{*}} a_{i}+\sum_{j=v(i)+1}^{m} \frac{\partial J}{\partial u_{i j}^{*}} u_{i j}
\end{aligned}
$$

by (20) and (21). Since $\mathrm{u}_{\mathrm{ij}}^{*}=0$ for $\mathrm{j}=\mathrm{v}(\mathrm{i})+1(1) \mathrm{m}$, then necessarily $\mathrm{u}_{\mathrm{ij}} \geq 0$ for $\mathrm{j}=\mathrm{v}(\mathrm{i})+1(1) \mathrm{m}$. Therefore,

$$
\sum_{j=1}^{v(i)} u_{i j}=a_{i}-\sum_{j=v(i)+1}^{m} u_{i j} .
$$

Substituting this in (24) we get for $\mathrm{i}=1(1) \mathrm{r}$,

$$
\begin{aligned}
& \sum_{j=1}^{m} \frac{\partial J}{\partial u_{i j}^{*}}\left(u_{i j}-u_{i j}^{*}\right)=\frac{\partial J}{\partial u_{i 1}^{*}}\left(a_{i}-\sum_{j=v(i)+1}^{m} u_{i j}\right) \\
& -\frac{\partial J}{\partial u_{i 1}^{*}} a_{i}+\sum_{j=v(i)+1}^{m} \frac{\partial J}{\partial u_{i j}^{*}} u_{i j} \\
& =\sum_{j=v(i)+1}^{m}\left(\frac{\partial J}{\partial u_{i j}^{*}}-\frac{\partial J}{\partial u_{i 1}^{*}}\right) u_{i j} \geq 0 .
\end{aligned}
$$

In a similar fashion, we consider (24) for $\mathrm{i}=\mathrm{r}+1(1) \mathrm{k}$. By (22) $\partial \mathrm{J} / \partial \mathrm{u}_{\mathrm{ij}}^{*}=0$ for $\mathrm{j}=1(1) \mathrm{v}(\mathrm{i})$ and $\mathrm{i}=\mathrm{r}+1(1) \mathrm{k}$; while $u_{i j}^{*}=0$ for $j=v(i)+1(1) m$. Therefore we get for $i=r+1(1)$ $\mathrm{k}$,

$$
\sum_{j=1}^{m} \frac{\partial J}{\partial u_{i j}^{*}}\left(u_{i j}-u_{i j}^{*}\right)=\sum_{j=v(i)+1}^{m} \frac{\partial J}{\partial u_{i j}^{*}} u_{i j} \geq 0 .
$$

From (26) and (27), we find that

$$
\sum_{\mathrm{i}=1}^{\mathrm{k}} \sum_{\mathrm{j}=1}^{\mathrm{m}} \frac{\partial \mathrm{J}}{\partial \mathrm{u}_{\mathrm{ij}}^{*}}\left(\mathrm{u}_{\mathrm{ij}}-\mathrm{u}_{\mathrm{ij}}^{*}\right) \geq 0
$$

hence $\mathrm{J}(\mathbf{U}) \geq \mathrm{J}\left(\mathbf{U}^{*}\right)+$ a non-negative quantity, i.e.,

$$
\mathrm{J}(\mathbf{U}) \geq \mathrm{J}\left(\mathbf{U}^{*}\right),
$$

and this completes the proof that the conditions of the theorem are sufficient as well as necessary.

\section{Example}

Suppose that some company operates $\mathrm{m}=2$ routes which are of different lengths. Let $A_{i}, i=1(1) 2$, be the set of airplanes which the company utilizes to satisfy the passenger demand for transportation on these routes. Let

$$
\mathrm{f}_{\mathrm{j}}(\mathrm{x} ;)=\sigma_{\mathrm{j}}^{-1} \exp \left(-\mathrm{x} / \sigma_{\mathrm{j}}\right), \mathrm{x}>0, \sigma_{\mathrm{j}}>0,
$$

represent the exponential probability density function of the passenger demand $\mathrm{X}$ for transportation on route $\mathrm{j}(\mathrm{j} \in\{1,2\})$, where $\sigma_{1}=100$ and $\sigma_{2}=150$.
It is required to minimize the expected total cost of operation (the performance index)

$$
J(\mathbf{U})=\sum_{j=1}^{2}\left[\sum_{i=1}^{2} w_{i j} u_{i j}+c_{j} \int_{Q_{j}}^{\infty}\left(x-Q_{j}\right) f_{j}(x) d x\right]
$$

subject to

$$
\sum_{j=1}^{2} u_{i j} \leq a_{i}, \quad i=1,2, \quad u_{i j} \geq 0,
$$

where

$$
\mathrm{Q}_{\mathrm{j}}=\sum_{\mathrm{i}=1}^{2} \mathrm{u}_{\mathrm{ij}} \mathrm{q}_{\mathrm{ij}}, \mathrm{j}=1,2,
$$

$\mathbf{U}=\left\{\mathrm{u}_{\mathrm{ij}}\right\}$ is the $2 \times 2$ matrix, $\mathrm{u}_{\mathrm{ij}}$ is the number of units of airplane $A_{i}$ allocated to the $j$ th route, $w_{i j}$ is the operation costs (in Euros) of airplane $A_{i}$ for the $j$ th route $\left(\mathrm{w}_{11}=900, \mathrm{w}_{12}=1000, \mathrm{w}_{21}=950, \mathrm{w}_{22}=1100\right), \mathrm{c}_{\mathbf{j}}$ is the price (in Euros) of a one-way ticket for air travel on the jth route $\left(c_{1}=55, c_{2}=70\right), q_{i j}$ is the limited seating capacity of airplane $A_{i}$ for the $j$ th route $\left(q_{11}=50, q_{12}=40, q_{21}=75\right.$, $\left.\mathrm{q}_{22}=60\right), \mathrm{a}_{\mathrm{i}}$ is the available number of units of airplane $A_{i}$ $\left(a_{1}=2, a_{2}=2\right)$.

It can be shown that the optimal solution is given by

$\mathrm{u}_{11}^{*}=1.83, \mathrm{u}_{12}^{*}=0.17, \mathrm{u}_{21}^{*}=0, \mathrm{u}_{22}^{*}=2 ; \mathrm{J}\left(\mathbf{U}^{*}\right)=10728.69$.

The optimal integer-valued solution is given by

$\mathrm{u}_{11}^{\bullet}=2, \stackrel{\bullet}{\bullet} \mathrm{u}_{12}=0, \mathrm{u}_{21}^{\bullet}=0, \mathrm{u}_{22}^{\bullet}=2 ; \mathrm{J}\left(\mathbf{U}^{\bullet}\right)=10741.29$.

\section{Conclusions}

Theorem 1 provides the necessary and sufficient conditions for an optimal allocation matrix, $\mathbf{U}^{*}$, and indicates the route to be followed to achieve that optimality, namely, we vary the allocation matrix $\mathbf{U}$ in such a way as to satisfy the conditions of Theorem 1 . Such manipulation can be performed in more than one way. Trial-and-error is one method, which has nothing to recommend it except perhaps the freedom to change the allocation arbitrarily. However, if coupled with sufficient insight, this procedure can yield quick results in comparatively small size problems. In large-size problems, however, it is not feasible to follow a trial-anderror technique. The number of possible combinations of allocation matrices to be varied at any stage can reach astronomical magnitudes. A rational, step-by-step procedure is therefore required, which converges on the optimality in a reasonable number of steps.

\section{Acknowledgments}

This work was supported in part by Research Grant No.02.0918 and Research Grant No.01.0031 from the 
Latvian Council of Science and the National Institute of Mathematics and Informatics of Latvia.

\section{References}

1. Nechval, N.A. Modern Statistical Methods of Operations Research. - Riga: RCAEI, 1982.

2. Nechval, N.A. Theory and Methods of Adaptive Control of Stochastic Processes. - Riga: RCAEI, 1984.

3. Nechval, N.A. A new efficient approach to constructing the minimum risk estimators of state of stochastic systems from the statistical data of small samples // Preprint of the 8th IFAC Symposium on
Identification and System Parameter Estimation, Beijing, P.R. China. - 1988. - P. 71-76.

4. Nechval, N.A., Nechval, K.N., Heimanis, B.M. Optimal rescheduling of airplanes under uncertainty // Proceedings of the Nordic Operations Research Conference (NOAS '97), University of Copenhagen, Denmark. - 1997. - P. 213-224.

5. Nechval, N.A., Nechval, K.N., Heimanis, B.M. Adaptive optimization in stochastic systems via the variation technique // CASYS (International Journal of Computing Anticipatory Systems). - 1999. - N 3. P. 317-328. 